\begin{tabular}{|c|c|c|}
\hline & International Journal of Current Research in & \\
\hline & Biosciences and Plant Biology & \\
\hline $\begin{array}{l}\text { DALLLLISHERS } \\
\text { PUBLISHER }\end{array}$ & $\begin{array}{c}\text { ISSN: 2349-8080 (Online) • Volume } 3 \bullet \text { Number } 4 \text { (April-2016) } \\
\text { Journal homepage: www.ijcrbp.com }\end{array}$ & \\
\hline
\end{tabular}

\title{
In Silico Docking Studies of Four Enzymes of Beauveria bassiana on the Subcellular Protein of Stored Product Pest, Corcyra cephalonica
}

\author{
S. Gowrilakshmi* and M. S. Nalina Sundari \\ Department of Zoology, Queen Mary's College, Mylapore, Chennai-6oo oo5, India \\ *Corresponding author.
}

\begin{abstract}
Entomopathogenic fungi Beauveria bassiana is being used as a biopesticide for various insect pests. Many field level usages were started long back but when it comes to the storage level the usage were minimized. In order to minimize the usage of synthetic chemical pesticide and to improve the biopesticide the present study was undertaken to control the stored product pest Corcyra cephalonica as it is the primary pest which causes economical agriculture loss to our country. B. bassiana secretes enzymes like amylase, protease, chitinase and lipase. These enzymes act on the protein present in the insect pests and bring death to the insect. These were verified by in silico docking studies and the enzyme amylase was found to be the best docking ligand.
\end{abstract}

\section{Article Info}

Accepted: 23 March 2016

Available Online: 06 April 2016

\section{Keywords}

Beauveria bassiana

Biopesticides

Entomopathogenic fungi

Mycoinsecticides

\section{Introduction}

Beauveria bassiana is a fungus that grows naturally in soils throughout the world and acts as a parasite on various arthropod species, causing white muscardine disease; it thus belongs to the entomopathogenic fungi. It is being used as a biological insecticide to control a number of pests such as termites, thrips, whiteflies, aphids and different beetles (Barbarin et al., 2012). Beauveria bassiana can be used as a biological insecticide to control a number of pests such as termites, whiteflies, and many other insects. Its use in the control of malaria-transmitting mosquitos is under investigation. As an insecticide, the spores are sprayed on affected crops as an emulsified suspension or wettable powder or applied to mosquito nets as a mosquito control agent.

As a species, Beauveria bassiana parasitizes a very wide range of arthropod hosts. However, different strains vary in their host ranges, some having rather narrow ranges, like strain Bba 5653 that is very virulent to the larvae of the Diamondback Moth and kills only few other types of caterpillars. Some strains do have a wide host range and should therefore be considered non-selective biological insecticides. These should not be applied to flowers visited by pollinating insects (EPA Factsheet, 2006).

\section{Corcyra cephalonica [The Rice Moth] \\ (http://www.iaszoology.com/corcyra-cephalonica/)}

Host: A pest of stored rice, millets and other cereals. Prefers broken grains and flour.

Damage: Caterpillars cause the damage by webbing together grains and forming lump and feed from inside it. Larvae before pupation wander about and leave a lot of webbing in the grains, causing excessive lumping, which reduces marketing quality of the grains.

Life cycle: Adults light greyish-brown in colour, 12 $\mathrm{mm}$ long and with a wing span of about $15 \mathrm{~mm}$, without any markings on the wings but veins are slightly darkened. Head bears a projected tuft of scales. Moths are short lived but realise a fecundity of 
150-200 eggs per female within a few days after emergence. Eggs are laid anywhere, on the grains, among grains, on the containers or on any surface near the grains, either singly or in clusters. Eggs are whitish, oval in shape, $0.5 \mathrm{~mm}$ long and having an incubation period of 4-5 days. Tiny larva after hatching is creamy-white, with a prominent head. It moves about actively and feeds on broken grains for some time and then starts spinning web to join grains. Full grown larva is pale whitish in colour, $15 \mathrm{~mm}$ long with short scattered hairs and no markings on body.
Larval period is $25-35$ days in summer and may be extended in winter. Pupation takes place inside an extremely tough, opaque whitish cocoon that is surrounded by webbed grains. Pupal period is about 10 days but may extend to 40-50 days to tide over winter moths. Moths commence mating and egg laying immediately after emergence. . The objective of this study is to check docking between the fungi Beauveria bassiana and insect pest Corcyra cephalonica so as to be used in Integrated Pest Management Systems as biopesticide.

\begin{tabular}{|c|c|}
\hline $\begin{array}{l}\text { Mnemonic } \\
\text { Taxon identifier } \\
\text { Scientific name } \\
\text { Common name } \\
\text { Synonym } \\
\text { Other names }\end{array}$ & $\begin{array}{l}\text { BEABA (http://www.uniprot.org/taxonomy/176275) } \\
176275 \\
\text { Beauveria bassiana } \\
\text { White muscardine disease fungus } \\
\text { Tritirachium shiotae } \\
\text { > ARSEF } 1564 \\
\text {, ARSEF } 7047 \\
\text { > BPI } 880999 \\
\text { > Beauveria bassiana (Bals.-Criv.) Vuill., } 1912 \\
\text { > Beauveria bassiana var. bassiana }\end{array}$ \\
\hline Lineage & 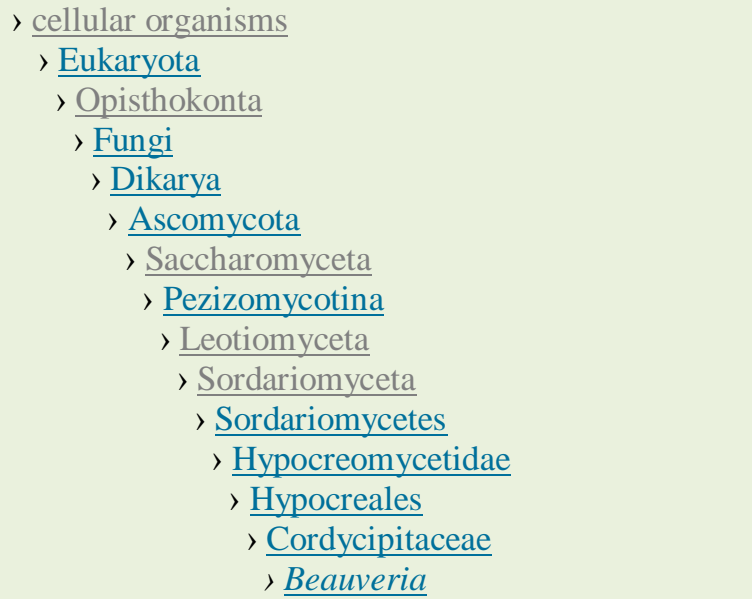 \\
\hline
\end{tabular}

\section{Beauveria bassiana}

Fungi with multifunctional lifestyles: Endophytic insect pathogenic fungi (Barelli et al., 2015): This study examines the symbiotic, evolutionary, proteomic and genetic basis for a group of fungi that occupy a specialized niche as insect pathogens as well as endophytes. We focus primarily on species in the genera Metarhizium and Beauveria, traditionally recognized as insect pathogenic fungi but are also found as plant symbionts. Phylogenetic evidence suggests that these fungi are more closely related to grass endophytes and diverged from that lineage ca. 100 MYA. We explore how the dual life cycles of these fungi as insect pathogens and endophytes are coupled. We discuss the evolution of insect pathogenesis while maintaining an endophytic lifestyle and provide examples of genes that may be involved in the transition toward insect pathogenicity. That is, some genes for insect pathogenesis may have been co-opted from genes involved in endophytic colonization. Other genes may be multifunctional and serve in both lifestyle capacities. The study suggested that their evolution as insect pathogens allowed them to effectively barter a specialized nitrogen source (i.e. insects) with host plants for photosynthate. These ubiquitous fungi may play an important role as plant growth promoters and have a potential reservoir of secondary metabolites.

Improving mycoinsecticides for insect biological control (Ortiz-Urquiza et al., 2015): The desire for decreased reliance on chemical pesticides continues to 
fuel interest in alternative means for pest control including the use of naturally occurring microbial insect pathogens. Insects, as vectors of disease causing agents or as agricultural pests, are responsible for millions of deaths and significant economic losses worldwide, placing stresses on productivity (GDP) and human health and welfare. In addition, alterations in climate change are likely to affect insect ranges, expanding their access to previously constrained geographic areas, a potentially worrisome outcome. Metarhizium anisopliae and Beauveria bassiana, two cosmopolitan fungal pathogens of insects found in almost all ecosystems, are the most commonly applied mycoinsecticides for a variety of insect control purposes. The availability of the complete genomes for both organisms coupled to robust technologies for their transformation has led to several advances in engineering these fungi for greater efficacy and/or utility in pest control applications. Here, we will provide an overview of the fungal-insect and fungalplant interactions that occur and highlight recent advances in the genetic engineering of these fungi. The latter work has resulted in the development of strains displaying (1) increased resistance to abiotic stress, (2) increased cuticular targeting and degradation, (3) increased virulence via expression of insecticidal protein/peptide toxins, (4) the ability to block transmission of disease causing agents, and (5) the ability to target specific insect hosts, decrease host fecundity, and/or alter insect behaviors.

Prospects for the use of biological control agents against Anoplophora in Europe (Brabbs et al., 2015): The study summarises the biological control of Anoplophora spp. (Coleoptera: Cerambycidae) and discusses its potential for use in Europe. Entomopathogenic fungi: Beauveria brongniartii Petch (Hypocreales: Cordycipitaceae) has already been developed into a commercial product in Japan, and fungal infection results in high mortality rates. Parasitic nematodes: Steinernema feltiae Filipjev (Rhabditida: Steinernematidae) and Steinernema carpocapsae Weiser have potential for use as biopesticides as an alternative to chemical treatments. Parasitoids: a parasitoid of Anoplophora chinensis Forster, Aprostocetus anoplophorae Delvare (Hymenoptera: Eulophidae), was discovered in Italy in 2002 and has been shown to be capable of parasitising up to $72 \%$ of A. chinensis eggs; some native European parasitoid species (e.g. Spathius erythrocephalus) also have potential to be used as biological control agents. Predators: two woodpecker (Piciformis: Picidae) species that are native to Europe, Dendrocopos major Beicki and Picus canus Gmelin, have been shown to be effective at controlling Anoplophora glabripennis in Chinese forests. The removal and destruction of infested and potentially infested trees is the main eradication strategy for Anoplophora spp. in Europe, but biological control agents could be used in the future to complement other management strategies, especially in locations where eradication is no longer possible.

\section{Corcyra cephalonica}

20-hydroxyecdysone mediates fat body arylphorin regulation during development of rice moth, Corcyra cephalonica (Venkat Rao et al 2016): Arylphorin hexamerins are one of the major insect storage proteins involved in diverse functions during metamorphosis. However, their regulation during development is not elucidated so far. In the present study, we documented 20-hydroxyecdysone (20E)-mediated regulation of arylphorin expression in the fat body of the stored grain pest, Corcyra cephalonica. Based on the differential developmental expression and 20E-induced transcriptional as well as translational level alterations of arylphorin, we isolated the 5' upstream region of the gene to analyze regulatory motifs. Promoter motif analysis revealed the presence of ecdysone response element (ERE). Transient transfection studies showed the functionality of the ERE. Enzyme mobility shift experiments with radiolabelled, cold and mutated probes indicate ERE-nuclear factor binding. This study is the first to report transcriptional regulation of arylphorins by $20 \mathrm{E}$ in lepdopteran insect species.

A novel Wolbachia strain from the rice moth Corcyra cephalonica induces reproductive incompatibility in the whitefly Bemisia tabaci: sequence typing combined with phenotypic evidence (Hu et al., 2015): Wolbachia are a group of maternally inherited bacteria frequently found in arthropods and filarial nematodes. They have recently attracted attention for their ecological roles in manipulating host reproduction, their potential use in biological control of pest insects and medical significance. Classification of Wolbachia strains is currently solely based on molecular methods. However, the strains even with identical sequence types may induce different host phenotypes. Here we isolated a Wolbachia strain from the rice moth Corcyra cephalonica (designated as wCcep_B_BJ), which was shown to share multilocus sequence typing and Wolbachia surface protein hypervariable region profiles with a cytoplasmic incompatibility $(\mathrm{CI})$-inducing strain in supergroup B, but the phenotype wCcep_B_BJ may 
induce needs to be determined. We thus transinfected it into the whitefly Bemisia tabaci harbouring an AWolbachia through nymphal microinjection. Fluorescent in situ hybridization demonstrated that wCcep_B_BJ was successfully transinfected into B. tabaci and transmitted to offspring through host eggs. Reciprocal cross showed that wCcep_B_BJ induced a strong bidirectional CI in the transinfected host without imposing a significant cost on female fecundity. Our results suggest that wCcep_B_BJ may be a promising strain for biocontrol of B. tabaci, an important agricultural pest insect.

Analysis of the Vitellogenin gene of rice moth, Corcyra cephalonica Stainton (Veerana et al 2014): Vitellogenin $(\mathrm{Vg})$ is a precursor of the major yolk protein, an essential nutrient for the embryonic development of oviparous animals including insects. Here, the gene (CceVg [Corcyra cephalonica $\mathrm{Vg}$ ] ) encoding the $\mathrm{Vg}(\mathrm{CceVg}$ of moth, $C$. cephalonica, was cloned and sequenced. The gene sequence was 6,721-bp long and contained 5five introns and six exons that together formed a 5,382-bp open reading frame. The deduced protein $(\mathrm{CceVg})$ consisted of 1,793 amino acid residues, including a 16amino-acid signal peptide. The putative molecular weight of the primary $\mathrm{Vg}$ protein was $202.46 \mathrm{kDa}$. The $\mathrm{CceVg}$ contained all conserved domains and motifs that were commonly found in most insect Vgs except the presence of a polyserine tract at the C-terminal region, which had not been reported in other lepidopteran Vgs. The expression pattern showed that $\mathrm{CceVg}$ was first transcribed at a very low level in the early larval stage but disappeared in later stage larva. In female, the $\mathrm{CceVg}$ mRNA was detected in early pupal stage and throughout adult stage. Interestingly, the $\mathrm{CceVg}$ mRNA was detected only in mated males at low levels, not in the virgin ones. Injection of $\mathrm{CceVg}$ double-stranded RNA into early-emergent females caused severely abnormal ovaries.

\section{Materials and methods}

Databases and tools used in the study are provided below with a flow chart (Flow Chart 1) showing the over view of in silico docking.

\section{Databases and Tools}

\section{Databases}

$$
\begin{aligned}
& >\text { SwissProt } \\
& >\text { Protein Data Bank }
\end{aligned}
$$

Tools
RasMol
$>$ Chem Sketch
$>$ ARGUSLAB
$>$ PyMol Viewer

Flow Chart 1. Over view of in silco docking studies.

Selection of Pathogenic disease
$\downarrow$
Selection of Macromolecule (Protein) responsible for
disease
$\downarrow$
Modelling 3D Structure [TOOl: Modeller 9.16]
$\downarrow$
Retrieving Inhibitors from PubChem Database
$\downarrow$
Drawing the 2D structure of inhibitor and converting to
$3 \mathrm{D}$
(ChemSketch)
$\downarrow$
Docking (ArgusLab)
$\downarrow$
Evaluation (PyMol Viewer)

\section{Structure retrieval}

Database similarly searches are one of the most important steps in analyzing a sequence. If the query sequence has a similar copy already in the database, a search will quickly reveal this fact. If a similarly of sequence or structure is found from another species, then they may be homologous (i.e., sequence that descended from common ancestral). This will pave a way for further analysis of the query sequence. The structure homologues for a given protein sequence query is searched against SwissProt and PDB.

\section{SwissProt}

Swiss-Prot is a curated biological database of protein sequences from different species created in 1986 by Amos Bairoch and developed by the Swiss Institute of Bioinformatics and the European Bioinformatics Institute. It strives to provide a high level of annotation (such as the description of the function of a protein, its domains structure, post-translational modifications, variants, etc.), a minimal level of redundancy and high level of integration with other databases.

Now founded by the NIH, SwissProt and its automatically curated supplement TrEMBL, have joined with the PIR (Protein Information Resource) to produce 
the Uniport Knowlegdebase, the world's most comprehensive catalogue of information on proteins. It is a central repository of protein sequence and function created by joining the information contained in swissprot, TrEMBL, and PIR. The UniportKB/Swiss-prot release 48.2 from 11 October 2005 contains 195,589 entries. Unifort is comprised of three components, each optimized for different uses. The UniPort knowledge (UniPort) is the central access point for extensive curated protein information, including function, classification and cross-reference. The UniPort non-redundant reference (UniRef) databases combine closely related sequences into a single record to speed searches. The UniPort Archive (UniParc) is a comprehencive repository, reflecting the history of all protein sequences. The proteins of Cytochrome b were retrieved from Swiss-Prot database. The accession numbers is: H6TG75.

\section{Names \& Taxonomy}

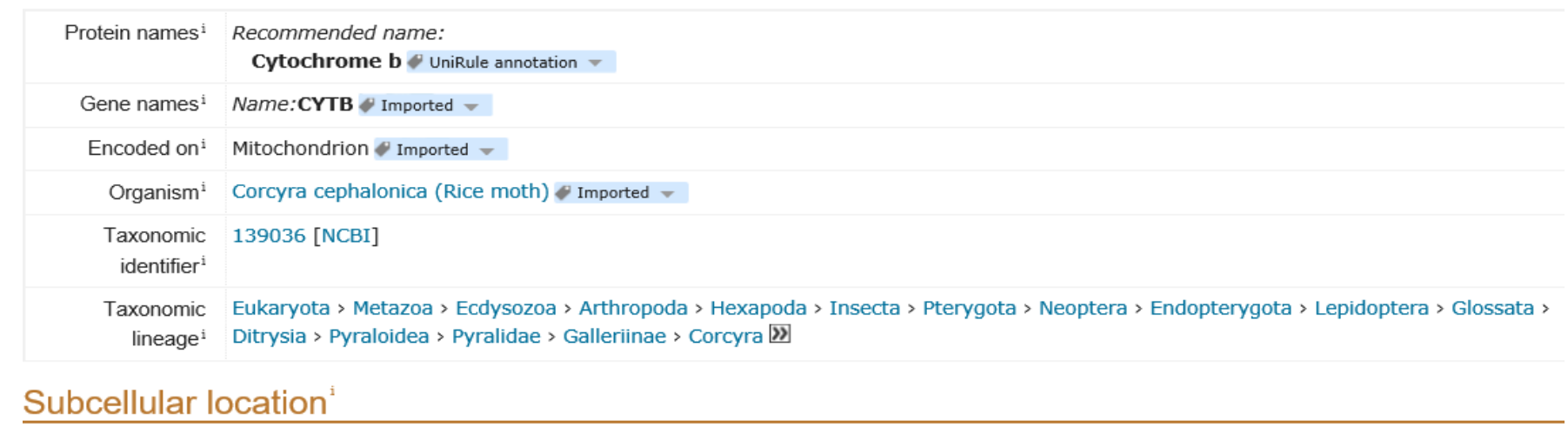

- Mitochondrion inner membrane UniRule annotation

Fig. 1: SwissProt Homepage of Cytochrome b protein.

\section{Protein Data [TEMPLATE SELECTION]}

The Protein Data Bank (PDB) is the single worldwide depository of information about the 3-D structures of large biological molecules, including proteins and nucleic acids. There are the molecules of life that are found in all organisms including bacteria, yeast, plants, flies and mice, and in healthy as well as diseased humans. Understanding the shape of a molecule helps to understand how it works. The RCSB PDB is a portal for information about these molecules, and as such enables research and education about the molecular basis of life. The PDB was established in 1971 at Brookhaven National Laboratory and originally contained 7 structures. In 1998, the research collaborator for structural bioinformatics (RCSB) became responsible for the management of the PDB. Details about the history, function, progress and future goals of the RCSB PDB can be found in the RCSB PDB Annual Reports and Newsletters. The RSCB PDB also maintains a historical record of its data, query and distribution systems.

The PDB is growing constantly and statistic on content growth is available. In 2004, 5360 experimentally determined structures were deposited from scientists all over the world. In addition to the huge growth in the numbers of structures, the complexity of the structures has also increased. Now there are several examples of large macromolecular machines in the database. Advances in science and technology have pushed the growth of the PDB as has changing attitudes about data sharing.

A variety of information associated with each structure is available through the RCSB PDB including sequence details, atomic coordinates and crystallization conditions; 3-D structure neighbours computed using various methods, derived geometric data, structure factors, 3-D images and a variety of links to other resources. Files in its holdings are deposited by the international user community and maintained by the RCSB PDB staff. Over 10000 scientists, students and educators from around the world visit the PDB website every day. Averages of 2.2 structures are downloaded every second. The data downloaded are used for research in biology and medicine as well as engineering and computer science.

The RCSB PDB Advisory committee is made up of an international team of experts in X-ray crystallography, Cryo-EM, NMR, modeling, bioinformatics and 
education. RCSB PDB appreciates the valuable feedback they provide on an ongoing basis. The RCSB is a member of the wwPDB (worldwide Protein Data Bank); a collaborative effort with the MSD-EBI (European Bioinformatics Institute-UK) and PDB (Protein Data Bank Japan) to ensure the PDB archives is global and uniform.

\section{PDBsum}

The PDBsum is a pictoral database that provides an ata-glance overview of the contents of each 3-D structure deposited in the protein data bank (PDB). It shows the molecule(s) that make up the structure (i.e., protein chains, DNA, ligands and metal ions) and schematic digrams of their interactions. Extensive use is made of the freely available RasMol molecular graphics program to view the molecules and their interactions in 3-D.

\section{Search}

Entries are accessed either by their 4-character PDB code, or by one of the two search boxes provided on the PDBsum homepage:

> Text search - which searches a given string against the TITLE, HEADER, COMPND, SOURCE, and AUTHOR records in the PDB. For a fuller description of the options that the search offers, see the website.

Sequence search - which performs a FASTA search of a given protein sequence against the sequences of all proteins in the PDB. The top hits are listed with links to their PDBsum pages.

\section{Browse}

You can also use any of the Browser options given on the PDBsum homepage such as:

* Highlights - tabulates some of the extreme structures in the database in terms of age, size, etc.

- List of PDB codes - lists all entries by their 4character code.

- Het Groups - lists all Het Groups in the PDB with links to the structures that contain them.
* Ligands - as for Het Groups, but consisting each bound molecule as a separate entity (often consisting of several covalently joined Het Groups).

* Enzymes - lists all enzyme structures in the PDB classed by the hierarchical E.C. numbering scheme. Also known as the Enzyme Structures Database or EC->PDB.

* ProSite - lists all PROSITE sequence patterns and the PDB entries that contain them.

* Species - classifies all PDB entries by the source species from which the protein comes as information presented on the PDBSum pages.

The information given on each PDB entry is spread across several pages, as listed below and accessible from the tabs at the top of the page. Only the relevant tabs will be present on any given page as follows:

Top page - summary information including thumbnail image of structure, molecules in structure, enzyme reaction diagram (where relevant), GO functional assignments and selected figures from key reference.

Protein - wiring diagram, topology diagram(s) by CATH domain and residue conservation (where available).

DNA/RNA - DNA/RNA sequence and NUCPLOT showing interactions made with protein.

Ligands - description of bound molecule and LIGPLOT showing interactions made with protein.

Prot-prot - schematic diagrams of any proteinprotein interfaces and the residue-residue interactions made across them.

Clefts - listing of top ten clefts in the protein, listed by volume with any bound ligands shown.

Links - links to external databases. 


\section{Modeller 9.16}

Step 1: Selection of Template [TOOL: BLAST]

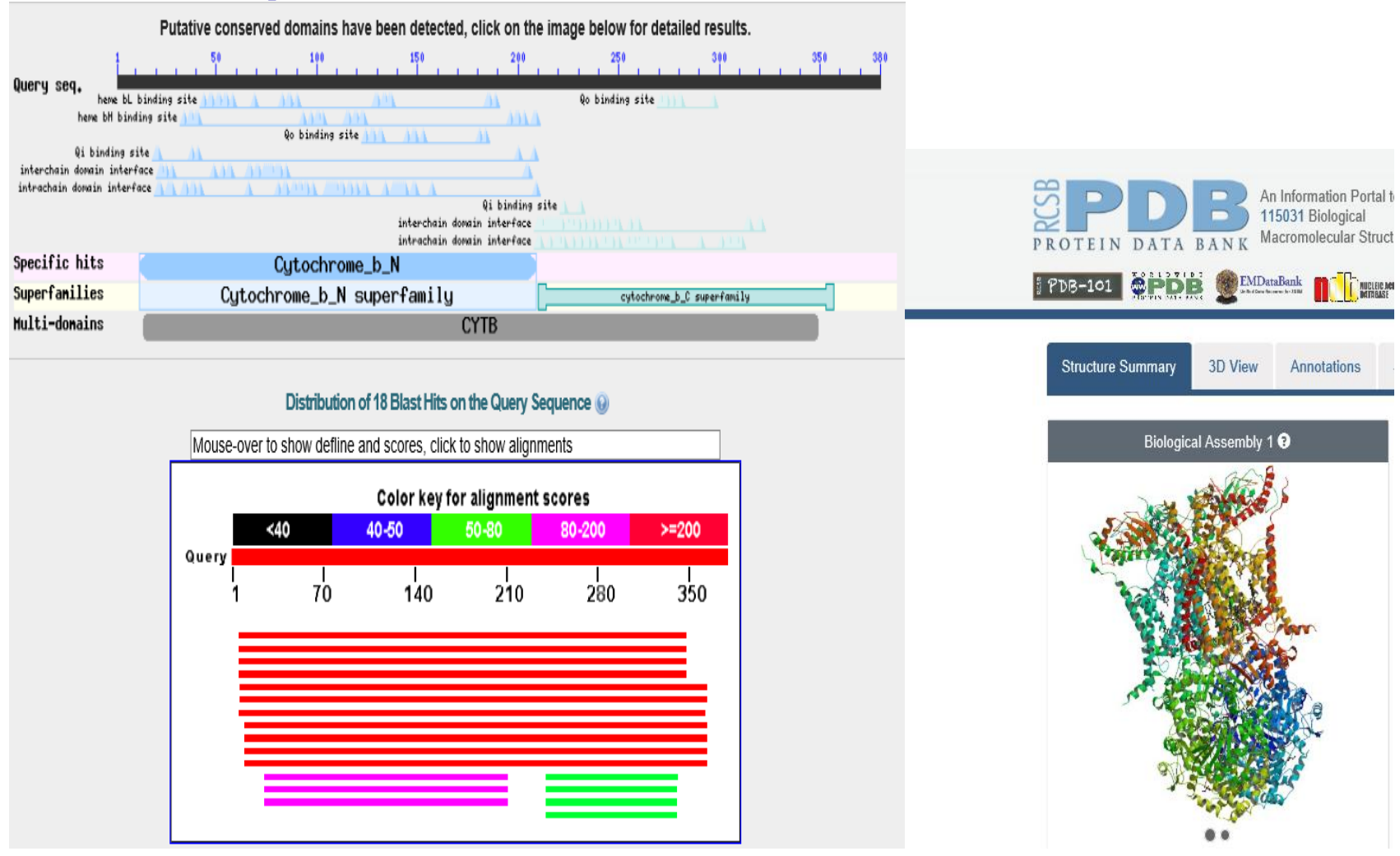

Step 2: Alignment between Template and Target

Chain C, Cytochrome Bc1 Complex From Chicken With Pfvs-Designed Moa Inhibitor Bound Sequence ID: pdb|3TGUIC Length: 380 Number of Matches: 1

$\triangleright$ See 3 more title(s)

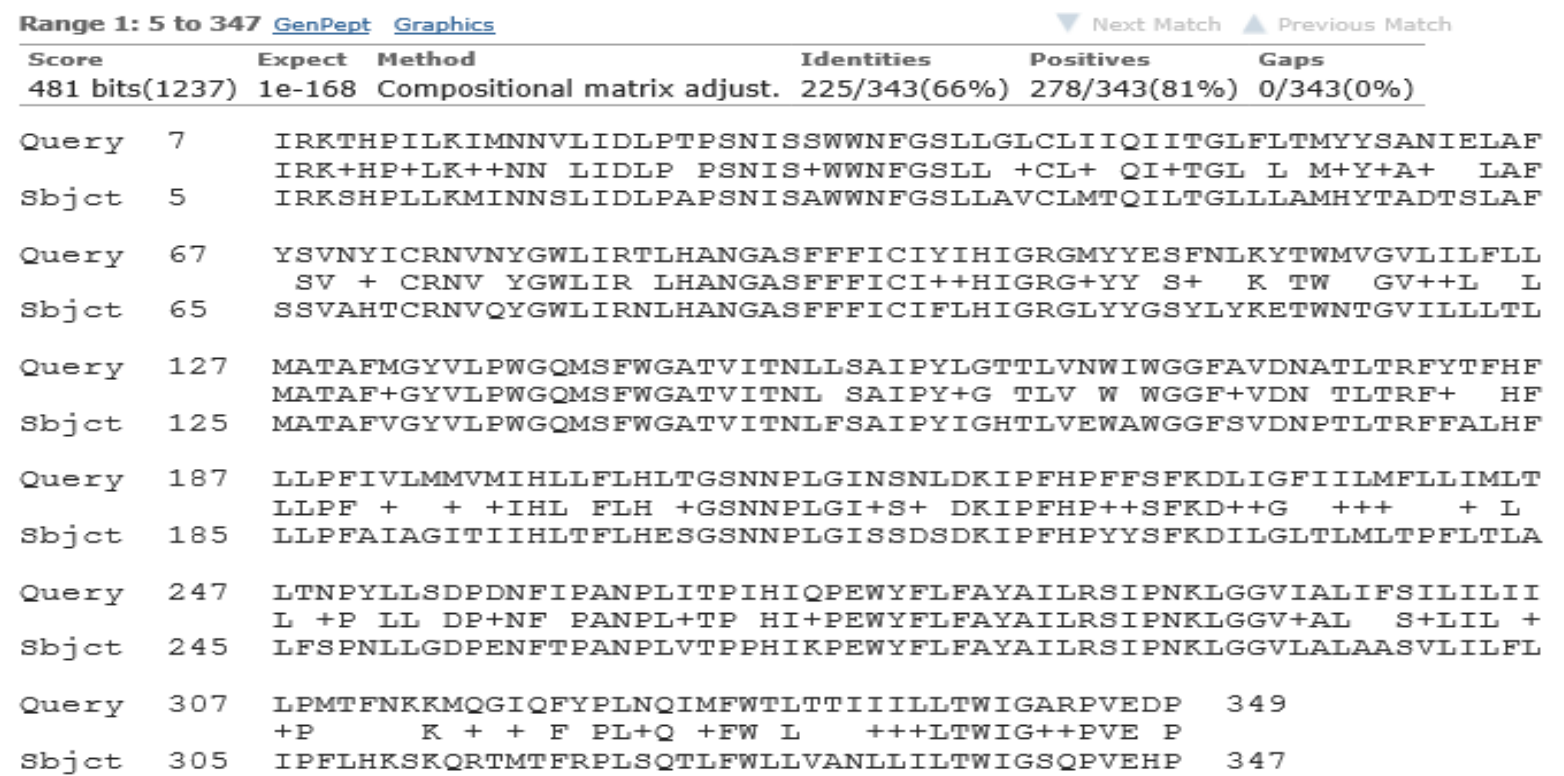

66 64 
Step 3: Building a Model [TOOL: RASMOL]

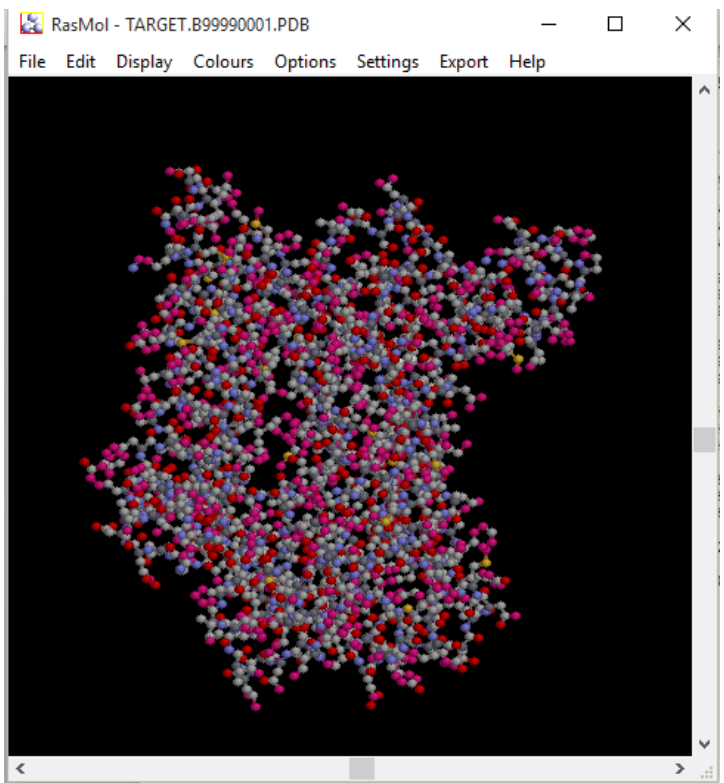

It is amazing that ChemSketch is freeware because it is a quite powerful chemical structure drawing program. One of its few drawbacks that is somewhat complicated to learn. However, the experience with drawing programs makes easier to learn. It's ACD/3D Viewer you can.

* Manipulate 3-D models, move, 2-D and 3-D rotate, resize, and change style and colours.

* Display a 3-D structure as stick, ball-and-stick, spheres, or disks.

* Add an overlay of small-dots at approximately the Van der Waals radius level to the solids 3-D structure.

* Measure and change bond lengths, plane bond angle and torsion angle.

* Optimize the structure using a 3-D CHARMm-type of force field.
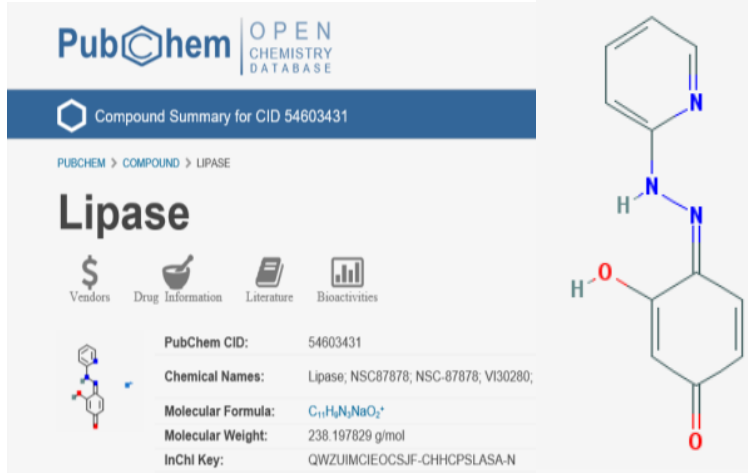

Switch from 3-D to 2-D display in the ChemSketch window at the click of a button.

* Set the 3-D molecule to Auto-rotate, with or without changing the style of structure display.

* View 3-D structure in perspective.

$\mathrm{ACD} / \mathrm{ChemSketch}$ has the following major capabilities such as

$\square$ Structure mode - for drawing chemical structure and calculating their properties.

Draw mode - for text and graphics processing.

Molecular properties - calculation for automatic estimation of:

$\square$ Formula weight

Index of refraction

Surface tension

Density

SSDielectric constant

Polarizabilitys

$\square$ Monoisotopic, norminal and average mass

ChemSketch has two modes: Structure and Draw. There are similarities and differences between them. Generates structural parts of the files such as atoms and bonds and the Draw mode allow you to enhance them with arrows, boxes and non-structure drawings. In both modes, there sure drop down dialog boxes and panels in which there are choices for different fonts, line widths, etc.

\section{Lipase}

Lipase is an enzyme of the hydrolase class that catalyzes the reaction of triacylglycerol and water to yield diacylglycerol and a fatty acid anion. It is produced by glands on the tongue and by the pancreas and initiates the digestion of dietary fats (From Dorland, 27th ed) EC 3.1.1.3.

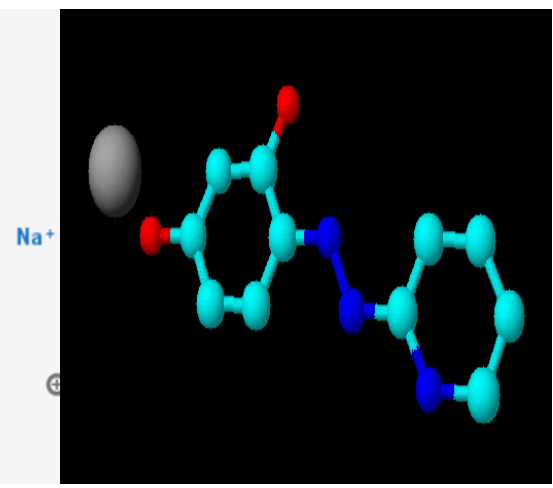

SMILES

$\mathrm{C} 1=\mathrm{CC}=\mathrm{NC}(=\mathrm{C} 1) \mathrm{NN}=\mathrm{C} 2 \mathrm{C}=\mathrm{CC}(=\mathrm{O}) \mathrm{C}=\mathrm{C} 2 \mathrm{O} \cdot[\mathrm{Na}+]$ 
Amylase

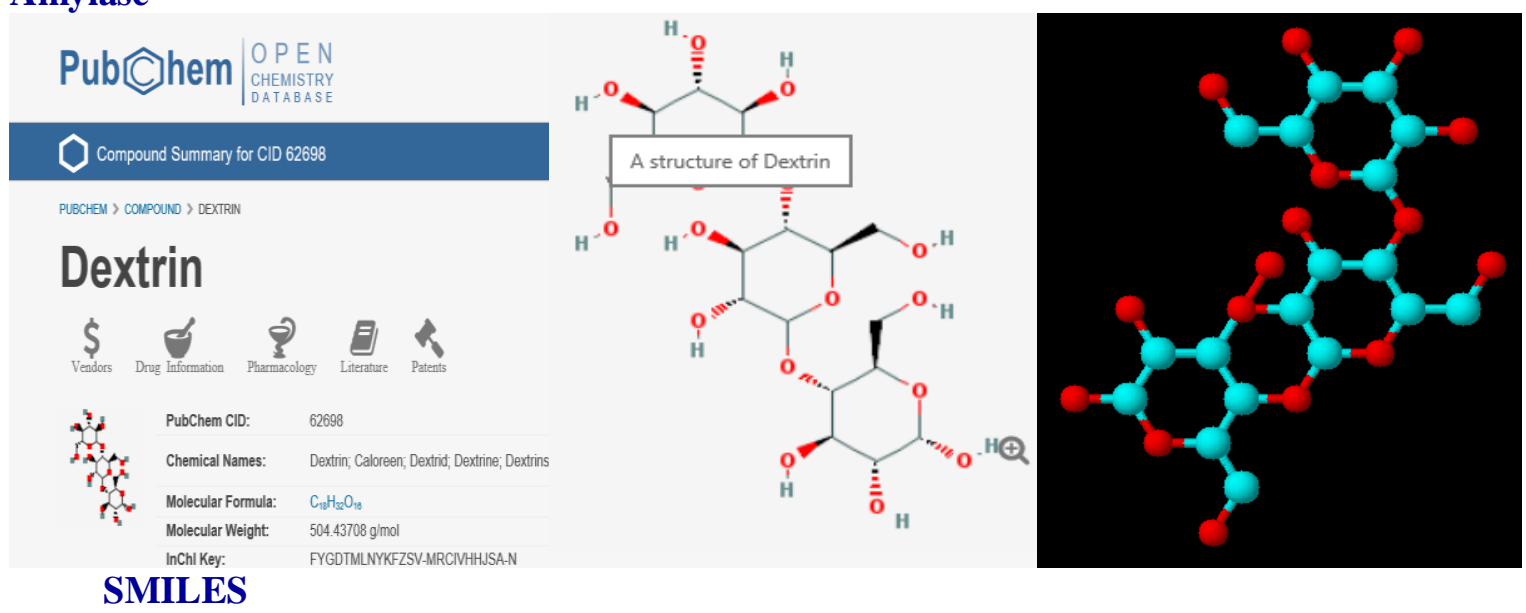

$\mathrm{C}(\mathrm{C} 1 \mathrm{C}(\mathrm{C}(\mathrm{C}(\mathrm{C}(\mathrm{O} 1) \mathrm{OC} 2 \mathrm{C}(\mathrm{OC}(\mathrm{C}(\mathrm{C} 2 \mathrm{O}) \mathrm{O}) \mathrm{OC} 3 \mathrm{C}(\mathrm{OC}(\mathrm{C}(\mathrm{C} 3 \mathrm{O}) \mathrm{O}) \mathrm{O}) \mathrm{CO}) \mathrm{CO}) \mathrm{O}) \mathrm{O}) \mathrm{O}) \mathrm{O}$

\section{Protease}

\section{Pub@]hem $\underset{\substack{\text { OPEMISTRY } \\ \text { DATABAS }}}{\operatorname{OP} \text { N }}$}

Compound Summary for CID 12000657

PUBCHEM > COMPOUND > CYSTEINE PROTEASE INHIBITOR

Cysteine Protease Inhibitor<smiles>[13CH2][13CH2][13CH2]</smiles>

PubChem CID:
Molecular Formula:
InChl Key:
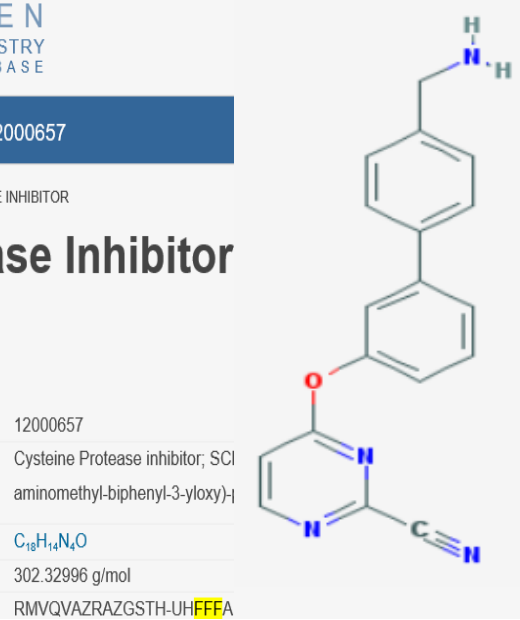

SMILES

RMVQVAZRAZGSTH-UHFFFA

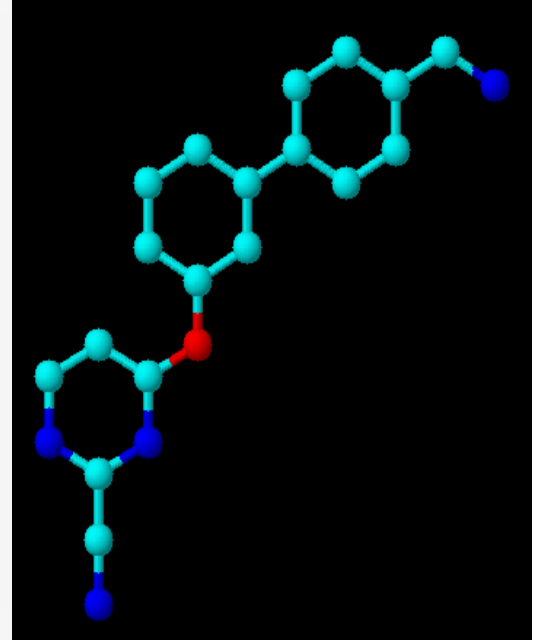

$\mathrm{C} 1=\mathrm{CC}(=\mathrm{CC}(=\mathrm{C} 1) \mathrm{OC} 2=\mathrm{NC}(=\mathrm{NC}=\mathrm{C} 2) \mathrm{C} \# \mathrm{~N}) \mathrm{C} 3=\mathrm{CC}=\mathrm{C}(\mathrm{C}=\mathrm{C} 3) \mathrm{CN}$

\section{Chitinase}

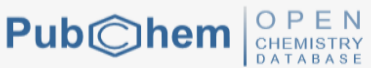

Compound Summary for CID 86223064

\section{Chitinase-IN-2}

$\$$
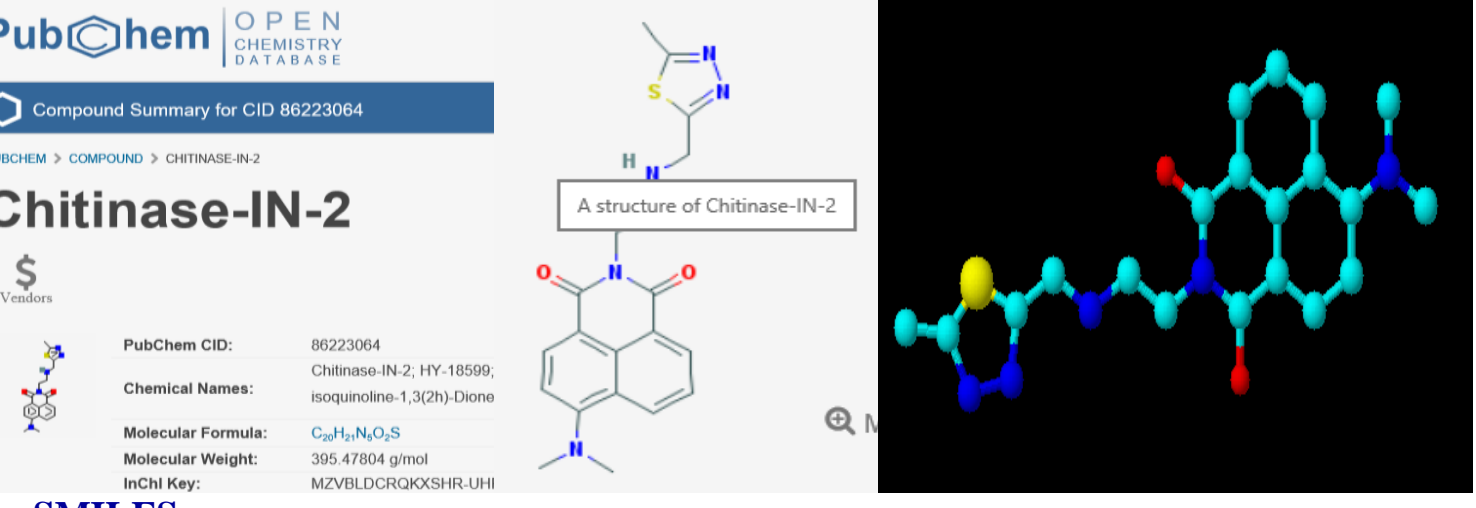

SMILES

$\mathrm{CC} 1=\mathrm{NN}=\mathrm{C}(\mathrm{S} 1) \mathrm{CNCCN} 2 \mathrm{C}(=\mathrm{O}) \mathrm{C} 3=\mathrm{C} 4 \mathrm{C}(=\mathrm{C}(\mathrm{C}=\mathrm{C} 3) \mathrm{N}(\mathrm{C}) \mathrm{C}) \mathrm{C}=\mathrm{CC}=\mathrm{C} 4 \mathrm{C} 2=\mathrm{O}$ 


\section{Docking: ARGUSLAB}

ArgusLab is a program to build graphic representations of molecular models. Using this program, you will be able to show molecular models to pupils, or even design matters by combining different elements. You will be able to include in your model several atoms, residues, groups and calculations (Fig. 2).

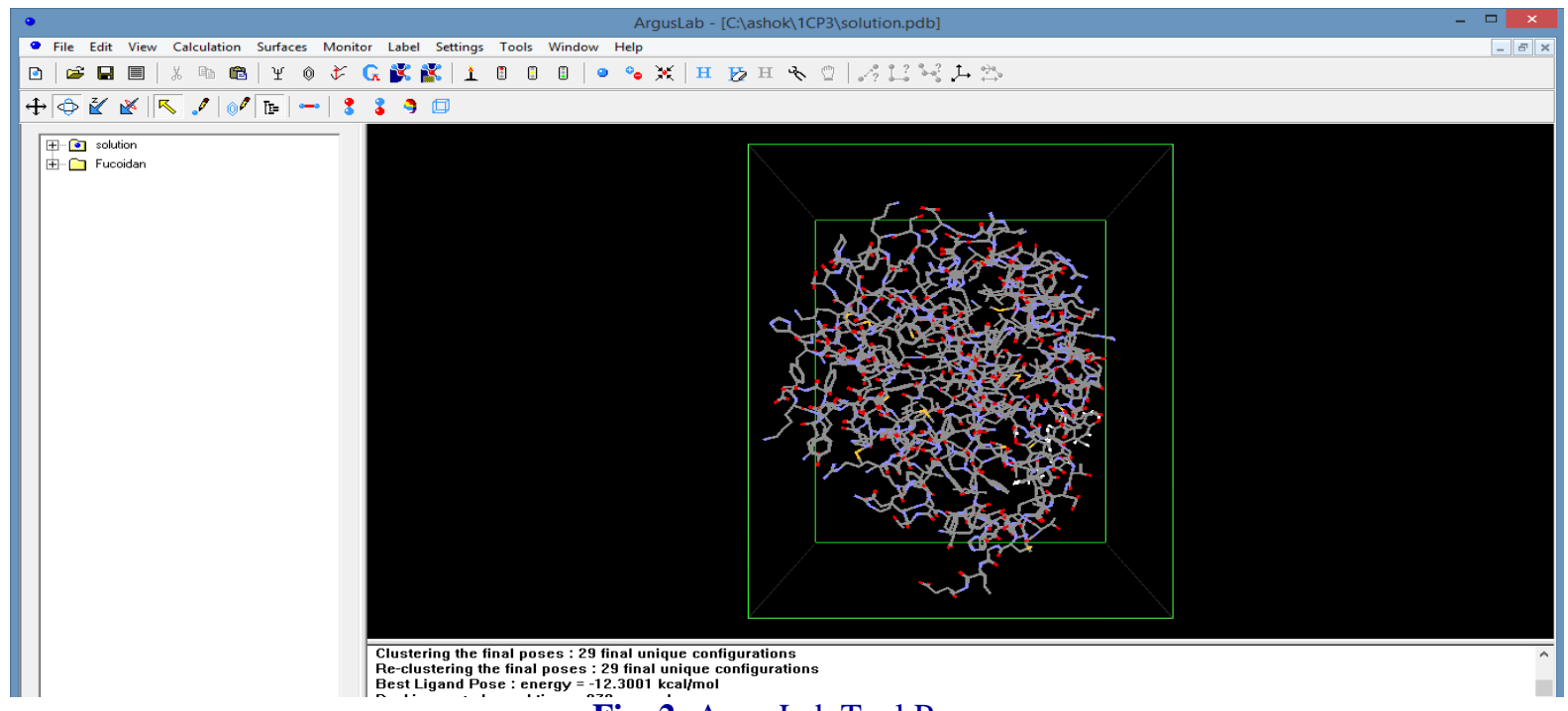

Fig. 2: ArgusLab Tool Page

\section{Visualization of Protein using PyMol Viewer}

The PyMol software interactively displays molecular models and creates publication quality images. A `ribbon drawing' is featured here. Space-filling, ball-and-stick representations, molecular surfaces, density map contours, and crystal packing diagrams, and movies are also supported.

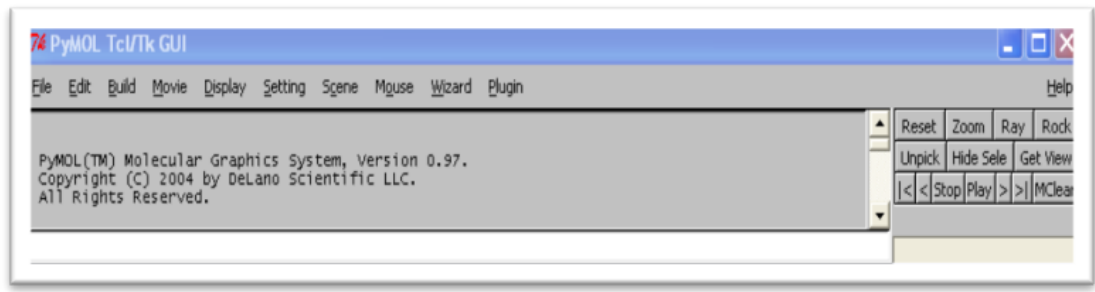

Fig. 3: PyMol Homepage.

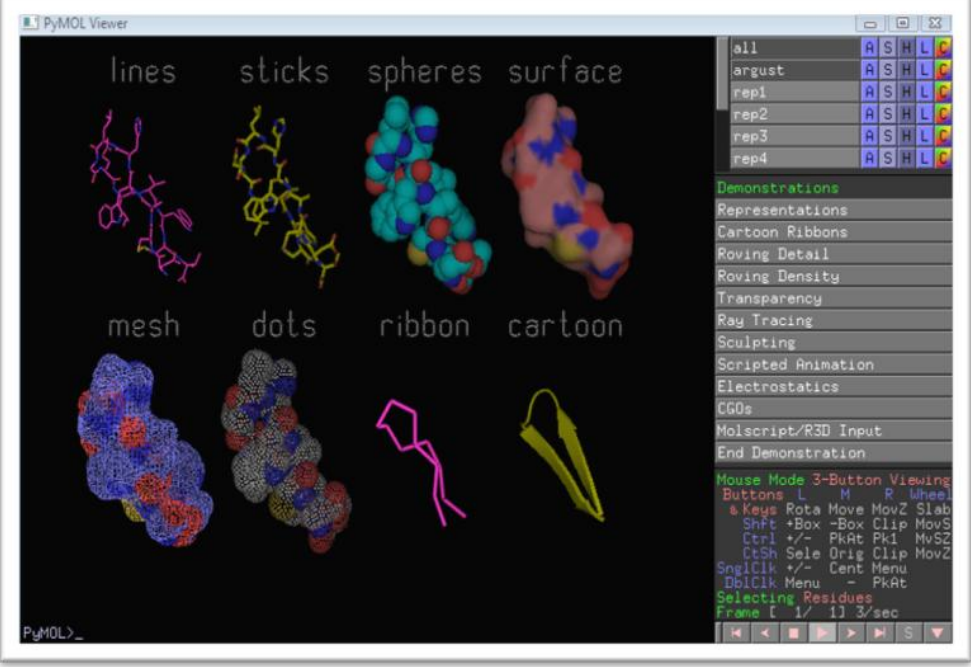

Note: The docked structures were then visualised using the PyMol Viewer software and the results were predicted. 


\section{Molecular docking studies}

For molecular docking studies of proteins Cytochrome b against the ligands LIPASE, AMYLASE, PROTEASE, CHITINASE, the protein structure was modelled using modeller tool version 9.16

\section{Retrieval of Protein Sequence from SWISS-PROT Database}

\section{Protein Name: Cytochrome b}

Swissprot ID: H6TG75

Organism: Corcyra cephalonica

Fasta Sequence:

>tr|H6TG75|H6TG75 CORCP Cytochrome b oS=Corcyra cephalonica $\mathrm{GN}=\mathrm{CYTB} \quad \mathrm{PE}=3 \quad \mathrm{SV}=1$

MNKF LP IRKTHP ILKIMNNVLI DLPTPSNISSWWNFGS LLGLCLIIQI ITGLFLTMYYSA NIELAFYSVNYICRNVNYGWLIRTLHANGASFFF IC IY I I IGRGMYYE SFNLKYTWMVGV LI LFLLMATAFMGYVLPWGQMS FWGATV ITNLLSAI PYLGTTLVNW IWGGFAVDNATLTR FYTFHFLLPF IVLMMVMI HLLF LHLTGSNNPLGINSNLDK I P FHPFFS FKDL I GF I I LMF LLIMLTLTNPYLLSDPDNFI PANPLITP IH IQPEWYFLFAYA ILRS I PNKLGGVIALIFS IL I L I I LPMT FNKKMOGIOFYP LNOIMFWTLTTI I I LLTW I GARPVEDPLHYYWTTSYYE LFFLLYFKSYCKKMLSWINL

\section{Protein location identification [TOOL: PSLpred]}

Fig. 4: Protein location identification.

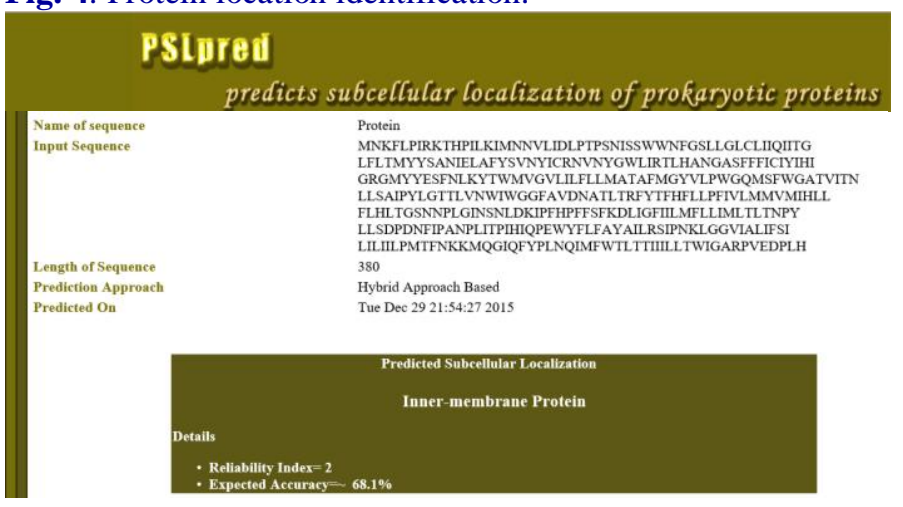

Docking [TOOL: ARGUSLAB]

\section{Cytochrome b}

\section{GRID SETTING}

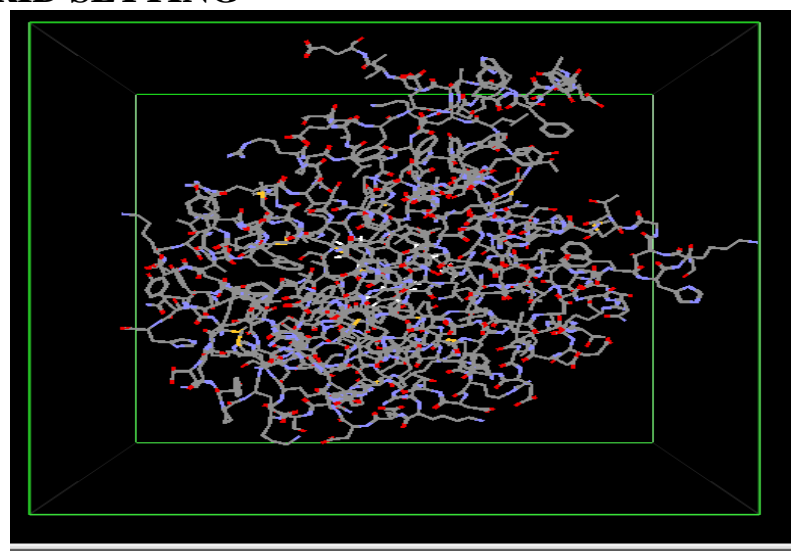

\section{Results and discussion}

The The sequence of Cytochrome b (H6TG75) was retrieved from SwissProt database. 3-D structure of Cytochrome b was modelled using Modeller Tool. The lipase, Amylase, Protease, Chitinase (ligands) compounds structure was drawn using ACD ChemSketch. The 3-D structure of Cytochrome b was docked with these four inhibitors using ArgusLab software.

The docking results were analyzed using PyMol visualization tool. In silico docking study revealed the interactions between ligand and protein by in silico molecular docking method in order to calculate the minimum binding energy $(\mathrm{kcal} / \mathrm{mol})$ between them and the docked result showed the docking score of -9.14 $\mathrm{kcal} / \mathrm{mol}$ for Cytochrome b- Lipase; $-8.12 \mathrm{kcal} / \mathrm{mol}$ for Cytochrome b- Amylase; $-13.63 \mathrm{kcal} / \mathrm{mol}$ for Cytochrome b-Protease; $\mathbf{- 1 2 . 2 7} \mathrm{kcal} / \mathrm{mol}$ for Cytochrome b- Chitinase. The interaction of Cytochrome b with Lipase forms 1 hydrogen bond; with Amylase 9 hydrogen bond; with Protease forms 2 hydrogen bonds; with Chitinase forms 2 hydrogen bonds.

This shows that there is a presence of binding site between the protein and four ligands. The docking is also valid by the formation of hydrogen bond between them. The results of the present study are provided hereunder following the sequence of the work done.

\section{Result of ArgusLab - docking of Cytochrome b with lipase}

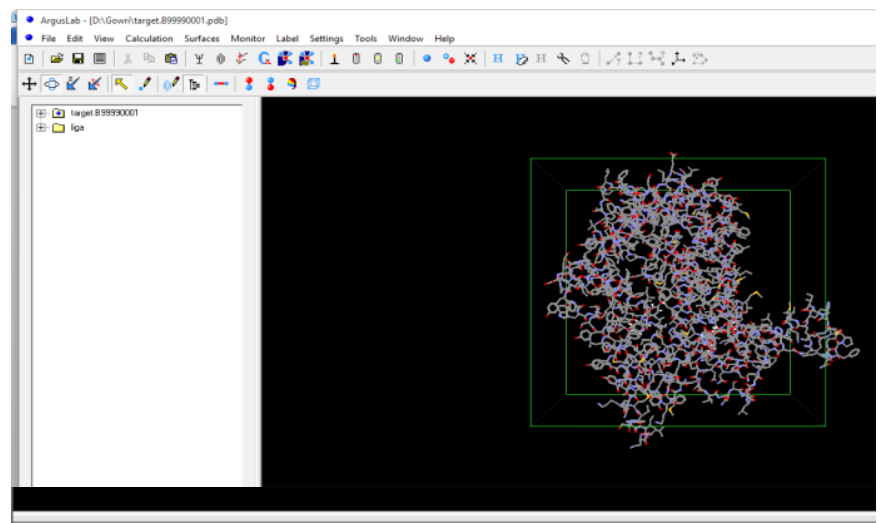

Clustering the final poses : 128 final unique configurations Re-clustering the final poses : 128 final unique configurations Best Ligand Pose : energy = $-9.14602 \mathrm{kcal} / \mathrm{mol}$ Docking run: elapsed time $=113$ seconds 
Visualization of Docked Comple using Pymol Tool

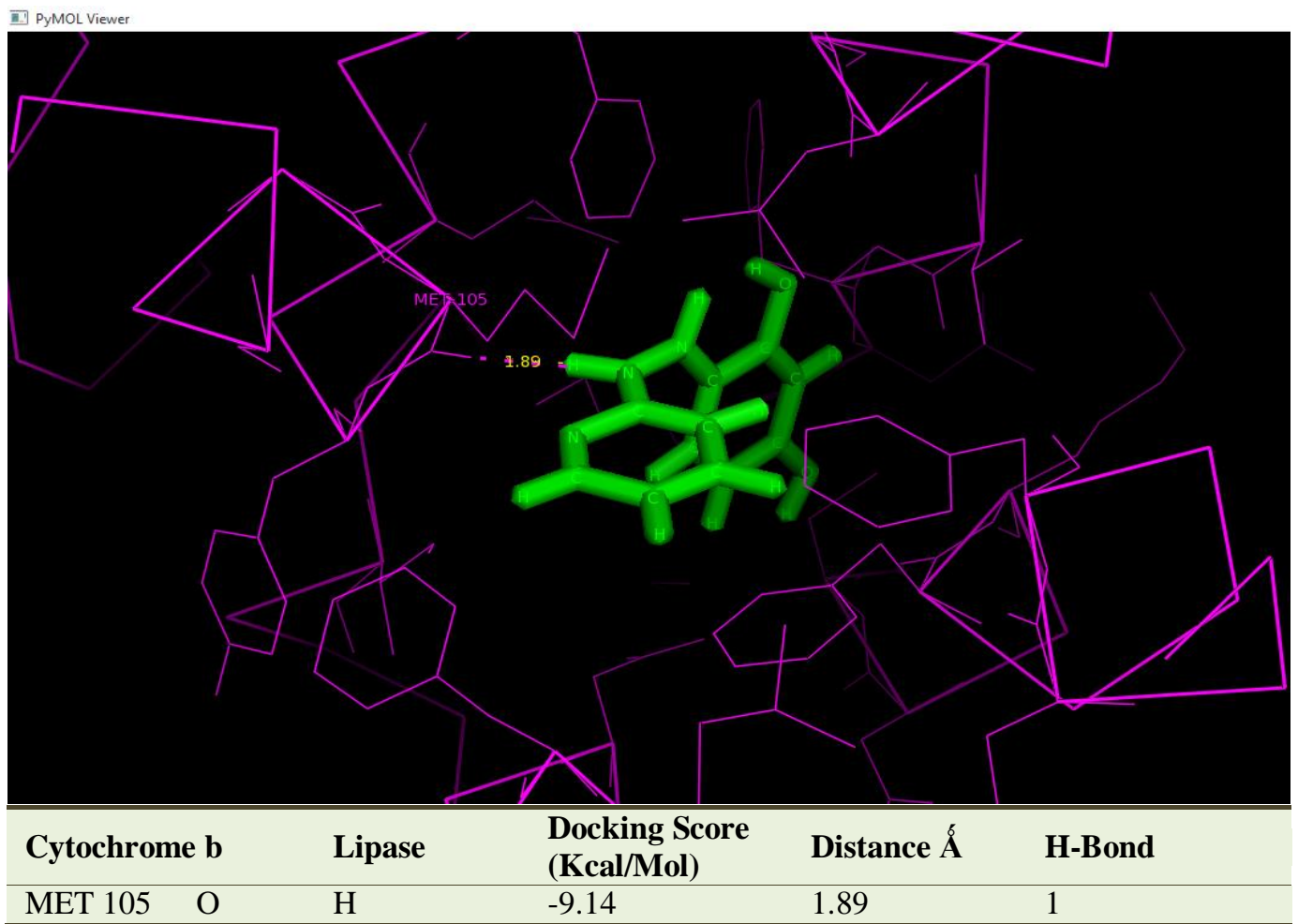

Result of ArgusLab - docking of Cytochrome b with Amylase

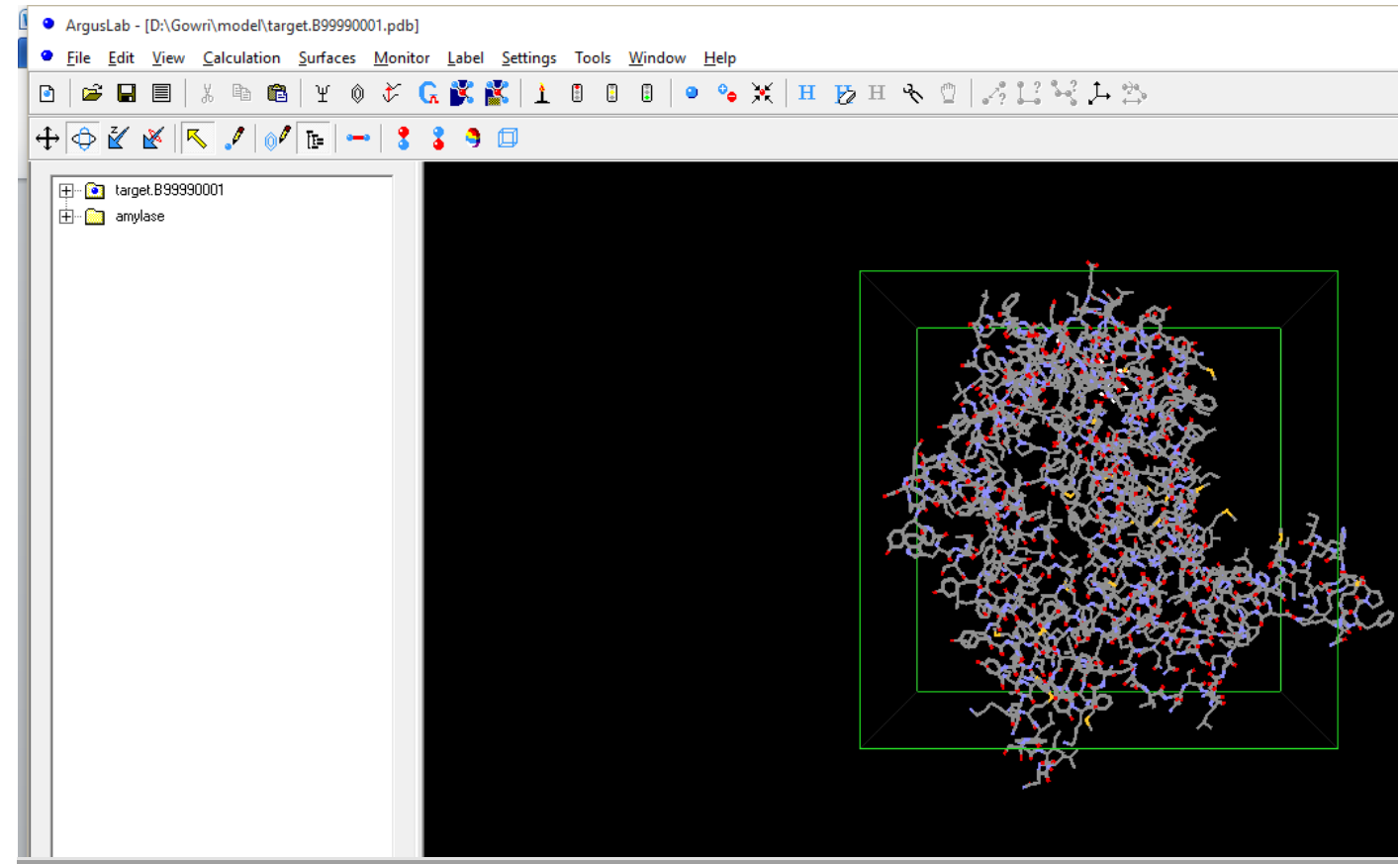

Clustering the final poses : 29 final unique configurations Re-clustering the final poses : 29 final unique configurations Best Ligand Pose : energy $=-8.12365 \mathrm{kcal} / \mathrm{mol}$ Dnr.kinn run: p.lansed time $=111$ se.rnnds 
Visualization of Docked Comple using Pymol Tool

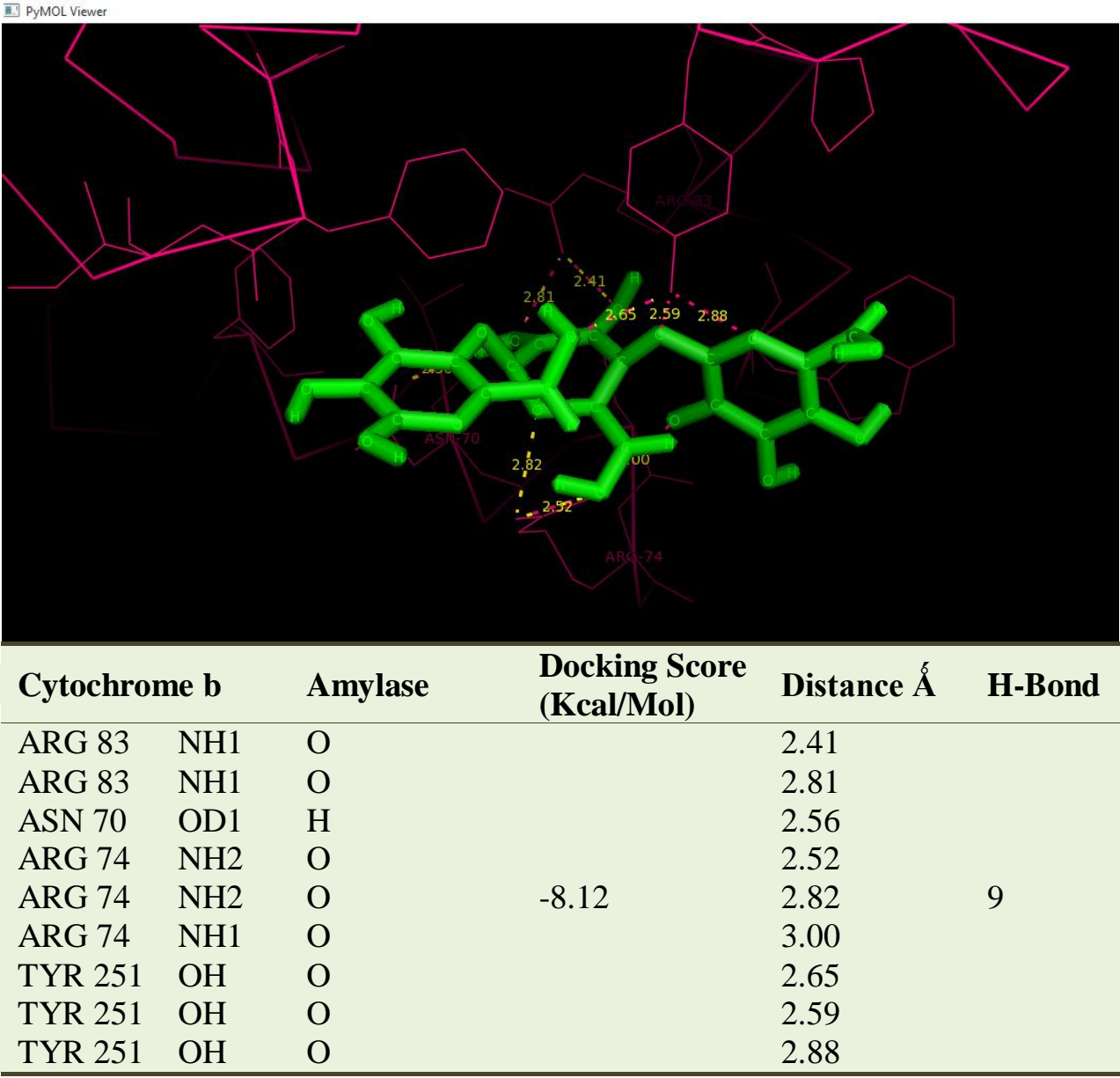

Result of ArgusLab-docking of Cytochrome b with Protease

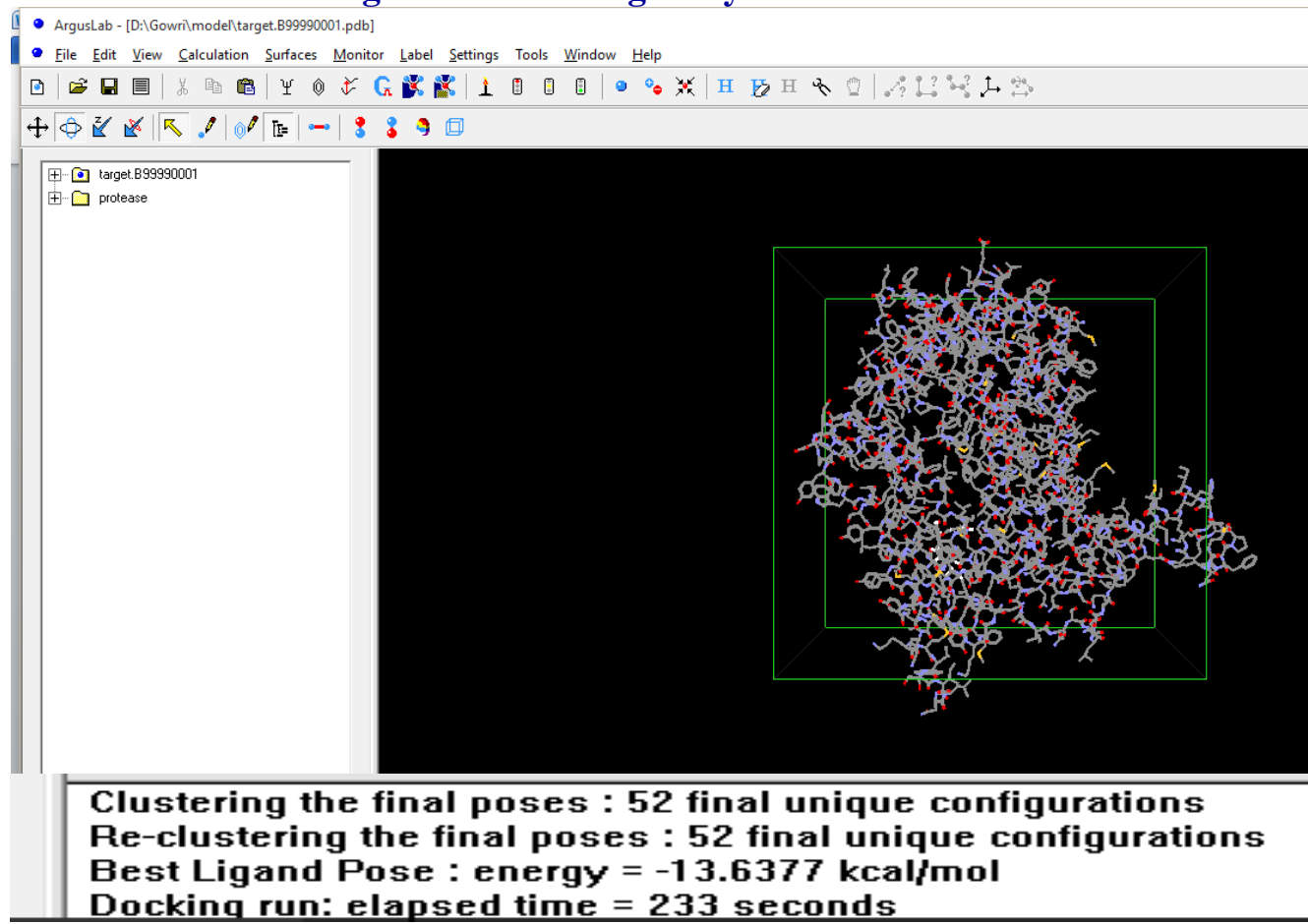


Visualization of Docked Comple using Pymol Tool

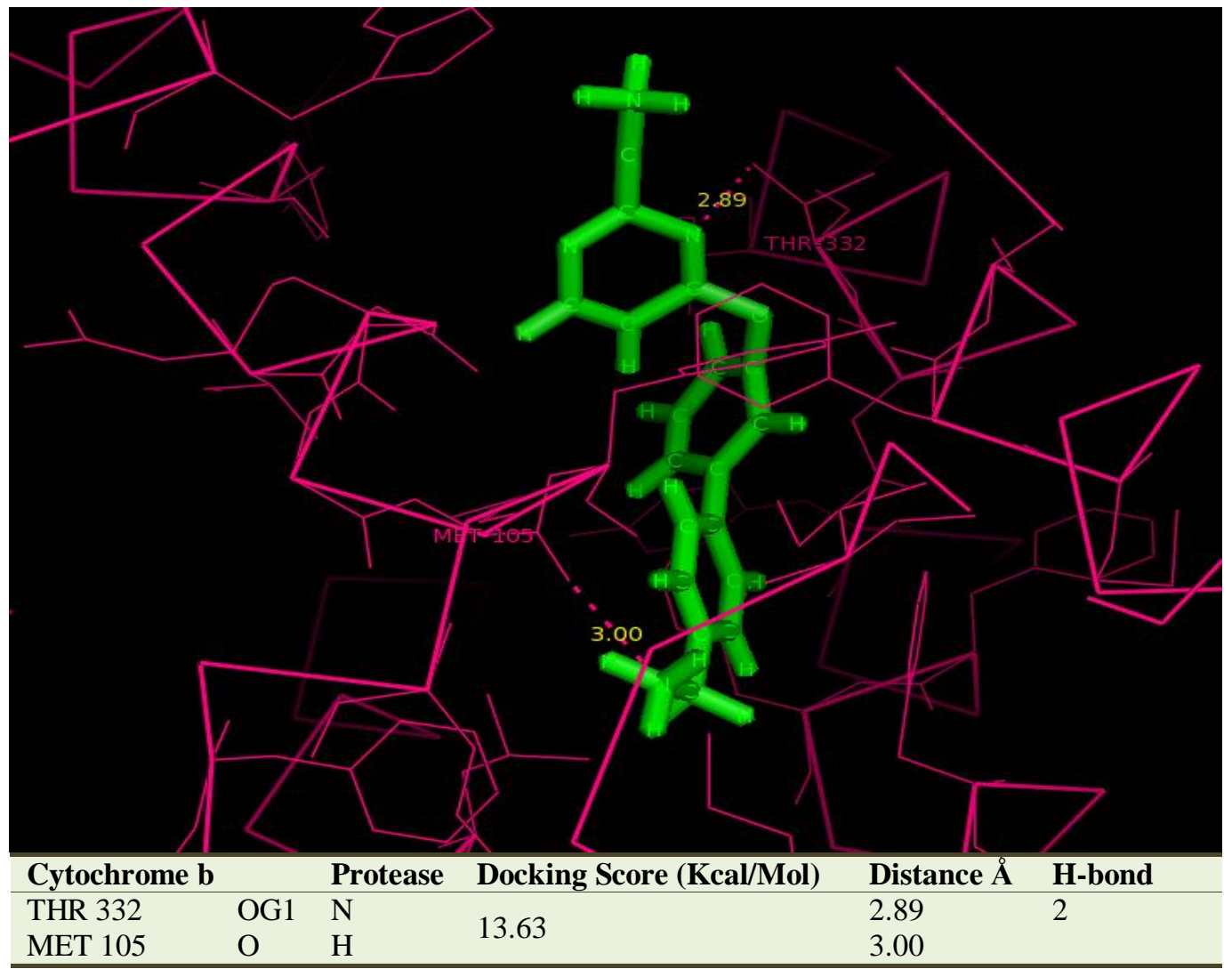

Result of ArgusLab-docking of Cytochrome b with Chitinase

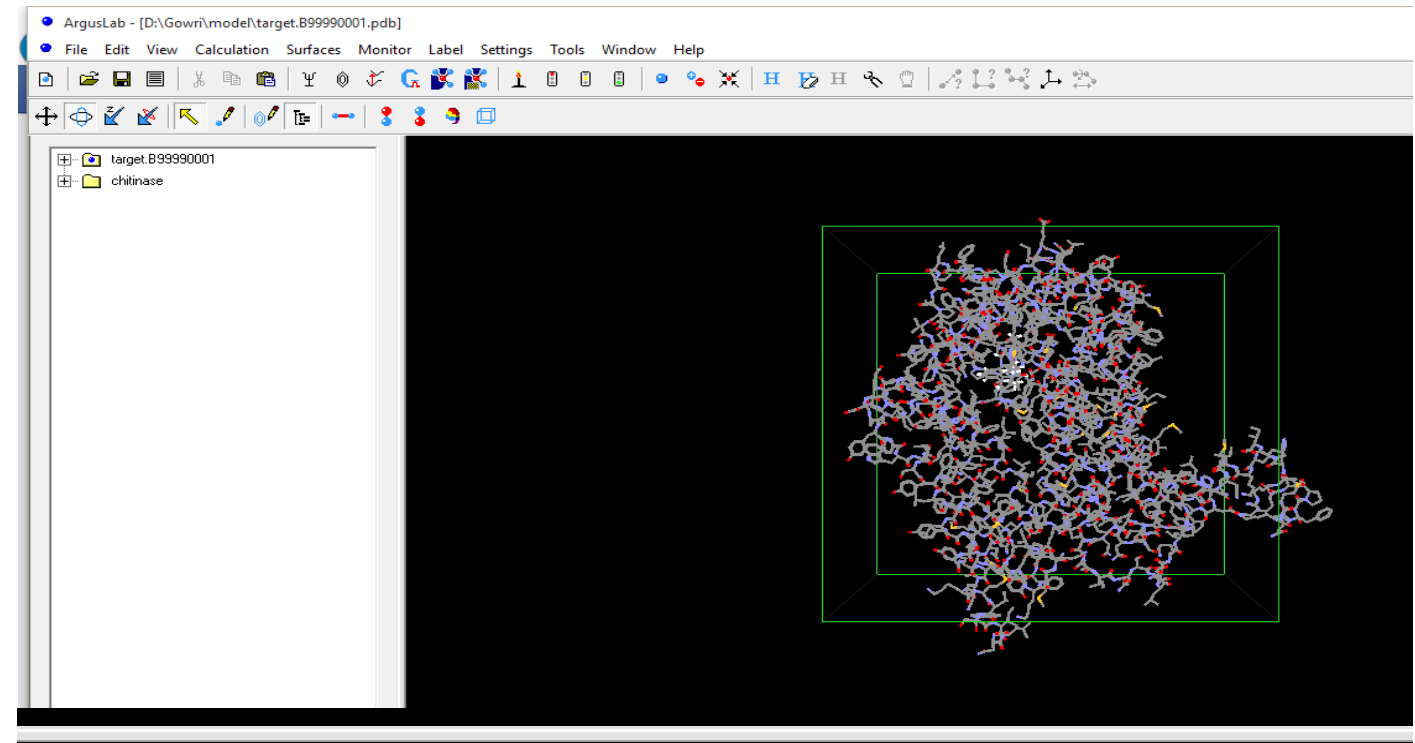

Clustering the final poses : 91 final unique configurations Re-clustering the final poses : 91 final unique configurations Best Ligand Pose : energy $=-12.2782 \mathrm{kcal} / \mathrm{mol}$

Dnrkinn run: plansed time $=144$ sernnds 


\section{Visualization of Docked Comple using Pymol Tool}

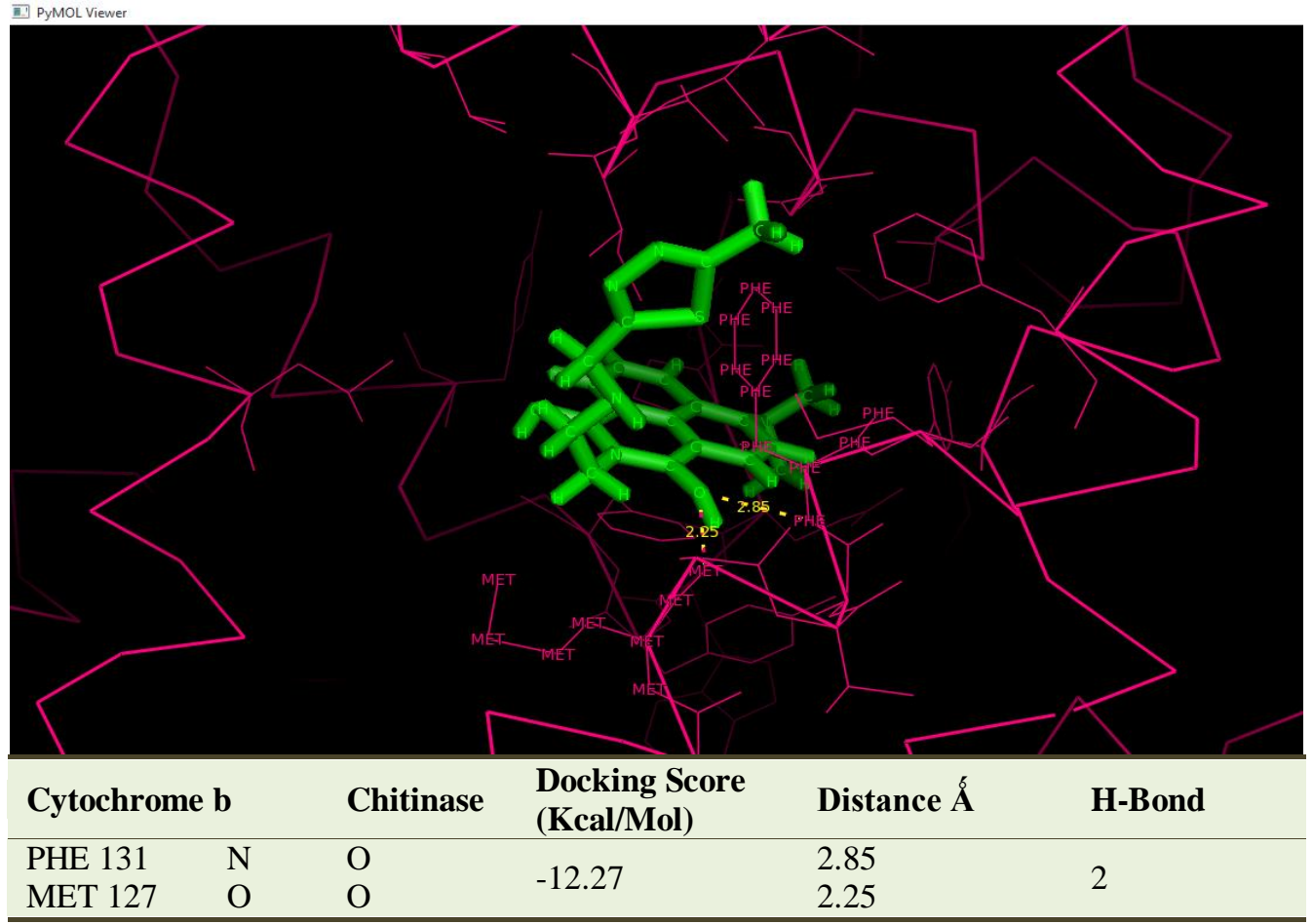

From the above docking results the Amylase docks well to these proteins which causes cellular degradation and brings death to the insect pest and is said to be the best compound. The result of Lipinski rule suggests that the analysed compound as the best biopesticide for the stored product pest Corcyra cephalonica. Docking study and in silico toxicity results proves the application of compounds as a potential and Biopesticide agents.

\section{Conflict of interest statement}

Authors declare that they have no conflict of interest.

\section{References}

Barbarin, A.M., Jenkins, N.E., Rajotte, E.G., Thomas, M.B., 2012. A preliminary evaluation of the potential of Beauveria bassiana for bed bug control (PDF). J. Invertebr. Pathol. 111(1), 82-85.

Barelli, L., Moonjely, S., Behie, S.W., Bidochka, M.J., 2015. Fungi with multifunctional lifestyles: endophytic insect pathogenic fungi. Plant Mol. Biol. 90(6), 657-664.
Brabbs, T., Collins, D., Hérard, F., Maspero, M., Eyre, D., 2015. Prospects for the use of biological control agents against Anoplophora in Europe. Pest. Manag. Sci., 71(1), 7-14.

EPA Factsheet. Retrieved 2006-12-14.

http://www.iaszoology.com/corcyra-cephalonica/.

http://www.uniprot.org/taxonomy/176275.

Hu, H.Y., Li, Z.X., 2015. A novel Wolbachia strain from the rice moth Corcyra cephalonica induces reproductive incompatibility in the whitefly Bemisia tabaci: sequence typing combined with phenotypic evidence. Environ. Microbiol. Rep. 7(3), 508-515.

Ortiz-Urquiza, A., Luo, Z., Keyhani, N.O., 2015. Improving mycoinsecticides for insect biological control. Appl. Microbiol. Biotechnol. 99(3), 1057-1068.

Veerana, M., Kubera, A., Ngernsiri, L., 2014. Analysis of the Vitellogenin gene of rice moth, Corcyra cephalonica Stainton. Arch. Insect. Biochem. Physiol. 87(3), 126-147.

VenkatRao, V., Chaitanya, R.K., Dutta-Gupta, A., 2016. 20hydroxyecdysone mediates fat body arylphorin regulation during development of rice moth, Corcyra cephalonica. Genetics. 575(2 Pt 3), 747-754.

\section{How to cite this article:}

Gowrilakshmi, S., Nalina Sundari, M.S., 2016. In silico docking studies of four enzymes of Beauveria bassiana on the subcellular protein of stored product pest, Corcyra cephalonica. Int. J. Curr. Res. Biosci. Plant Biol. 3(4), 91-105. doi: http://dx.doi.org/10.20546/ijcrbp.2016.304.014 